\title{
STUDY OF DEPRESSION IN WOMEN WITH CERVICAL AND BREAST CANCER
}

Nimisha Mishra ${ }^{1}$, Rajeev Dwivedi²

\section{HOW TO CITE THIS ARTICLE:}

Nimisha Mishra, Rajeev Dwivedi. "Study of Depression in Women with Cervical and Breast Cancer". Journal of Evolution of Medical and Dental Sciences 2015; Vol. 4, Issue 12, February 09; Page: 1936-1943,

DOI: $10.14260 /$ jemds/2015/281

ABSTRACT: BACKGROUND: There is considerable lack of scientific estimate of depressive disorder among cancer patients in India. OBJECTIVES: (1) To associate the depressive disorders between the cervical cancer and breast cancer patients and (2) to compare the level of depression score among cervical and breast cancer patients, and with medically ill inpatient population with some other medical illnesses. SETTING AND DESIGN: A cross-sectional study at inpatient Department of Bharath Cancer Hospital and JSS Medical College Hospital, Mysore. MATERIAL AND METHOD: The study was conducted on admitted thirty breast and thirty cervical cancer inpatients in medical ward of JSS Hospital and Bharath Cancer Hospital, Mysore from December 2007 to august 2009. Data analysis was done for the both groups of cancer and with thirty control group of medically ill inpatient population with some other medical illnesses. Detailed psychological, sociodemographic characteristics were recorded in proforma specially designed for the study. Depression was assessed using MINI plus, HAMD scale and scoring was done. STATISTICAL ANALYSIS: Descriptive statistics, Cross tabs procedure, repeated measure ANOVA statistical methods were carried out through the SPSS for Windows (version 16.0). RESULTS: Major depressive disorder was present in $16.7 \%$ of breast cancer and $23.3 \%$ of cervical cancer patients.. There was no significant association between type of cancer (Breast cancer and cervical cancer) and depressive disorder. Depression score was found high in cervical cancer cases compare to breast cancer cases though difference in these scores were not statistically significant in between two cancer groups. Depression score was high and significant in both cancer groups as compare to control group. CONCLUSION: Depression is more prevalent in cancer patients than in other several medical illneses and adequate knowledge is required for psychosocial interventions and designing programs aimed at improving the quality of life of cancer patients.

KEYWORDS: Cervical cancer, breast cancer, depression.

INTRODUCTION: In recent years with advances made in oncology, the survival rates of patients diagnosed as having cancer has improved. Consequently the focus has shifted from treatment to improving the quality of life of the survivors. This has prompted mental health professionals to be increasingly involved in the care of these patients, helping them in coping with the diagnosis and treatment of cancer through appropriate interventions. There is a sizeable literature available regarding the prevalence of psychiatric disorders among cancer patients and on the outcome of intervention in this population. 1,2 $^{2}$

Most of these studies in this field are from the West and very few are from India. ${ }^{3}$ As a result, there is little systematic information currently available on the nature and occurrence of psychiatric conditions among this important group of patients in India. This study was undertaken to contribute to the growing body of literature in psycho-oncology worldwide, especially as data in this respect is limited for Indian population and is intended to detect any significant association in depressive disorder between breast and cervical cancer patients. 


\section{ORIGINAL ARTICLE}

MATERIALS AND METHOD: STUDY AREA: The study was conducted in the inpatient Department of Bharath Cancer Hospital and JSS Medical College Hospital, Mysore.

Study: The study was cross sectional in design; subjects were recruited on a purposive basis from the in-patient Department of JSS Hospital and Bharath Cancer Hospital, Mysore from December 2007 to august 2009. The recruited subjects were divided into three groups based on medical diagnosis: breast cancer group, cervical cancer group and control group.

Experimental Groups were the patients admitted in JSS Hospital and Bharath Cancer Hospital, with cervical or breast cancer, in the age of 20-65 years of female sex, who gave written informed consent, were selected for the study. 30 patients in each cervical and breast cancer group fulfilling the criteria were selected for study. Patients with neurological impairment due to stroke, secondary to trauma, multiple sclerosis, history of hypothyroidism, intracranial space occupying lesions and prior history of psychiatric illness and who are unaware of their diagnosis were excluded from study.

Control group subjects were female patients of age group 20-65 years admitted in general medical ward of JSS Medical College and Hospital for some other medical illnesses, not having cancer and consented for the study. The evaluating tools used were:

1. Sociodemograhic and health proforma.

2. Socio economic rating scale (SES) (S. E. Gupta and B. P Sethi-1978).

3. Mini International Neuropsychiatric interview (M.I.N.I Plus).

4. Hamilton rating scale for depression (HAM-D).

PROCEDURE: The order of presentation of instruments were kept identical for all subjects. The instruments were administered in single session of 30-60 minutes duration approximate. Each case was evaluated and discussed with a senior psychiatrist and diagnosed as per the DSM-IV TR criterias. The level of depression was assessed with above mentioned tools. Medical data were obtained from subjects and their medical records Data was collected and statistical analysis was done using descriptive statistics, Cross tabs procedure, Repeated measure ANOVA statistical methods through SPSS for Windows (version 16.0).

RESULTS: General socio-demographic and medical aspects of the study Population: The majority of women in study were in the age of 46 to 55 years. 23(80\%)subjects of cervical cancer patients were from rural area and 17 (56.7\%)subjects of breast cancer were from urban area. $19(63.3 \%)$ subjects of cervical cancer group were from lower middle socioeconomic status and majority of breast cancer subjects $(43.3 \%)$ were from middle socioeconomic status. In this study all patients and controls were married.

There was no significant difference in between cervical cancer and breast cancer group on socio demographic and illness variables. $56.7 \%$ of breast cancer subjects were from urban background and $80 \%$ of cervical cancer subjects were from rural background which was significant $(\mathrm{P}=0.003) .33 .3 \%$. This reflects the urban and rural distribution of breast and cervical cancer and occurrence of cervical cancer more in lower socio-economic status. Table 1 shows sociodemographic variables for the groups. 


\section{ORIGINAL ARTICLE}

\begin{tabular}{|c|c|c|c|c|c|}
\hline & & Breast cancer & Cervical cancer & Control & Total \\
\hline \multirow{4}{*}{$\begin{array}{c}\text { Age range } \\
\text { (yrs) }\end{array}$} & $26-35$ & $\begin{array}{c}4 \\
13.3 \%\end{array}$ & $\begin{array}{c}1 \\
3.3 \%\end{array}$ & - & $\begin{array}{c}5 \\
5.6 \%\end{array}$ \\
\hline & $36-45$ & $\begin{array}{c}6 \\
(20.0 \%)\end{array}$ & $\begin{array}{c}9 \\
30.0 \%\end{array}$ & $\begin{array}{c}2 \\
6.7 \%\end{array}$ & $\begin{array}{c}17 \\
18.9 \%\end{array}$ \\
\hline & $46-55$ & $\begin{array}{c}14 \\
46.7 \%\end{array}$ & $\begin{array}{c}13 \\
43.3 \%\end{array}$ & $\begin{array}{c}25 \\
83.3 \%\end{array}$ & $\begin{array}{c}52 \\
57.8 \%\end{array}$ \\
\hline & $>56$ & $\begin{array}{c}6 \\
20.0 \%\end{array}$ & $\begin{array}{c}7 \\
23.3 \%\end{array}$ & $\begin{array}{c}3 \\
10.0 \%\end{array}$ & $\begin{array}{c}16 \\
17.8 \%\end{array}$ \\
\hline Marital status & & $\begin{array}{c}30 \\
100 \% \\
\end{array}$ & $\begin{array}{c}30 \\
100 \% \\
\end{array}$ & $\begin{array}{c}30 \\
100 \% \\
\end{array}$ & $\begin{array}{c}90 \\
100 \% \\
\end{array}$ \\
\hline \multirow[t]{2}{*}{ Domicile } & Urban & $\begin{array}{c}17 \\
56.7 \% \\
\end{array}$ & $\begin{array}{c}6 \\
20.0 \% \\
\end{array}$ & $\begin{array}{c}7 \\
23.3 \% \\
\end{array}$ & $\begin{array}{c}30 \\
33.3 \% \\
\end{array}$ \\
\hline & Rural & $\begin{array}{c}13 \\
43.3 \% \\
\end{array}$ & $\begin{array}{c}24 \\
80.0 \% \\
\end{array}$ & $\begin{array}{c}23 \\
76.7 \% \\
\end{array}$ & $\begin{array}{c}60 \\
66.7 \% \\
\end{array}$ \\
\hline \multirow{3}{*}{$\begin{array}{c}\text { Socio economic } \\
\text { status }\end{array}$} & Middle & $\begin{array}{c}13 \\
43.3 \%\end{array}$ & $\begin{array}{c}11 \\
36.7 \%\end{array}$ & $\begin{array}{c}7 \\
23.3 \%\end{array}$ & $\begin{array}{c}31 \\
34.4 \%\end{array}$ \\
\hline & Lower middle & $\begin{array}{c}12 \\
40.0 \%\end{array}$ & $\begin{array}{c}19 \\
63.3 \%\end{array}$ & $\begin{array}{c}22 \\
73.3 \%\end{array}$ & $\begin{array}{c}53 \\
58.9 \%\end{array}$ \\
\hline & Upper middle & $\begin{array}{c}5 \\
16.7 \%\end{array}$ & 0 & $\begin{array}{c}1 \\
3.3 \%\end{array}$ & $\begin{array}{c}6 \\
6.7 \%\end{array}$ \\
\hline
\end{tabular}

Table 1: Comparison of socio-demographic profile of the subjects

\begin{tabular}{|c|c|c|c|c|c|}
\hline DISORDER & No/Yes & $\begin{array}{c}\text { Breast } \\
\text { cancer(n) }\end{array}$ & $\begin{array}{c}\text { Cervical } \\
\text { cancer(n) }\end{array}$ & $\begin{array}{c}\text { Control } \\
\mathbf{n}\end{array}$ & $\begin{array}{c}\text { Total } \\
\mathbf{N}\end{array}$ \\
\hline \multirow{2}{*}{$\begin{array}{c}\text { Major } \\
\text { depressive } \\
\text { disorder }\end{array}$} & No & $25(83.3 \%)$ & $23(76.7 \%)$ & $29(96.7 \%)$ & $77(85.6 \%)$ \\
\cline { 2 - 6 } & Yes & $5(16.7 \%)$ & $7(23.3 \%)$ & $1(3.3 \%)$ & $13(14.4 \%)$ \\
\cline { 2 - 6 } Dysthymia & Total & $\mathbf{3 0 ( 1 0 0 \% )}$ & $\mathbf{3 0 ( 1 0 0 \% )}$ & $\mathbf{3 0 ( 1 0 0 \% )}$ & $\mathbf{9 0 ( 1 0 0 \% )}$ \\
\cline { 2 - 6 } & Yes & $27(90.0 \%)$ & $27(90.0 \%)$ & $28(93.3 \%)$ & $82(91.1 \%)$ \\
\cline { 2 - 6 } & Total & $3(10.0 \%)$ & $3(10.0 \%)$ & $2(6.7 \%)$ & $8(8.9 \%)$ \\
\hline \multicolumn{7}{|c|}{ Table 2: Association of breast cancer, cervical cancer and } \\
control group with depressive disorders & $\mathbf{9 0}(\mathbf{1 0 0} \%)$ \\
\hline
\end{tabular}

The study results showed 5 (16.7\%) subjects of breast cancer and 7 (23.3\%) subjects of cervical cancer had major depressive distorder while only 1 (3.3\%) control was diagnosed to have major depressive disorder..There was no significant association between the type of cancer(breast and cervical) and depressive disorder. Dysthymia was present in 3 (10\%)of breast cancer cases and 3 (10\%)of cervical cancer cases subject. Putting them together 8 cases (26.66\%) of breast cancer 


\section{ORIGINAL ARTICLE}

group, 10 cases (33.33\%) of cerical cancer group and 3 (10\%)subjects of control group, diagnosed as having depressive disorder (including major depressive disorder and dysthymia).Table 2 and fig 1 showing association of breast cancer, cervical cancer and control group with depression.

Fig. 1: Association of breast cancer, cervical cancer and control group with major depression.

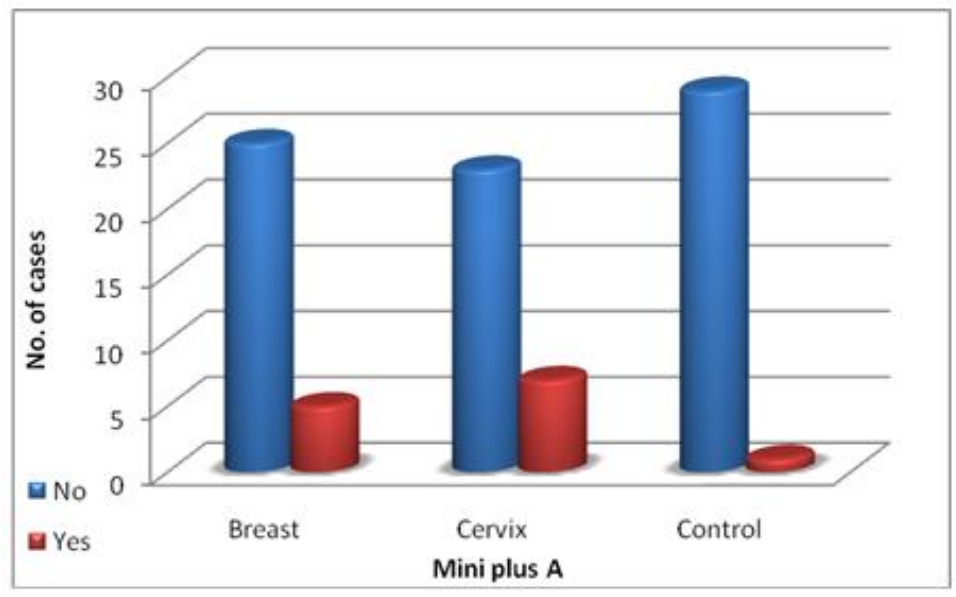

Fig. 1

MINI Plus A; Major Depressive Disorder.

t-Test for equality of mean between breast cancer, and cervical cancer on HAMD-17 scores showed no significant difference in individual items as well as in total scores between breast and cervical cancer groups. HAMD-16th item (loss of weight) weight showed significant difference in the mean of breast (mean=0.56) and cervical (mean=0.80) cancer (Fig. 2).

Fig. 2: mean values of hamilton depression rating scale 17 items in breast cancer, cervical cancer, and control group.

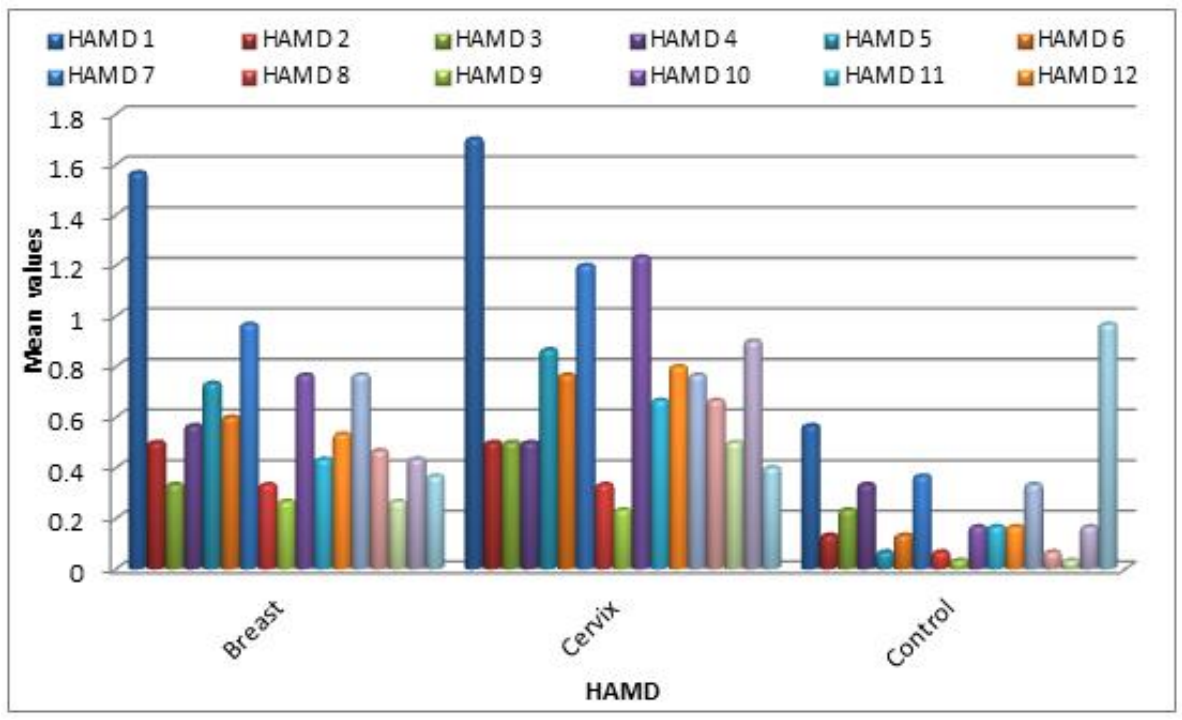

Fig. 2 


\section{ORIGINAL ARTICLE}

Fig. 3: Mean values of total hamilton depression rating scale in breast cancer, cervical cancer, and control group.

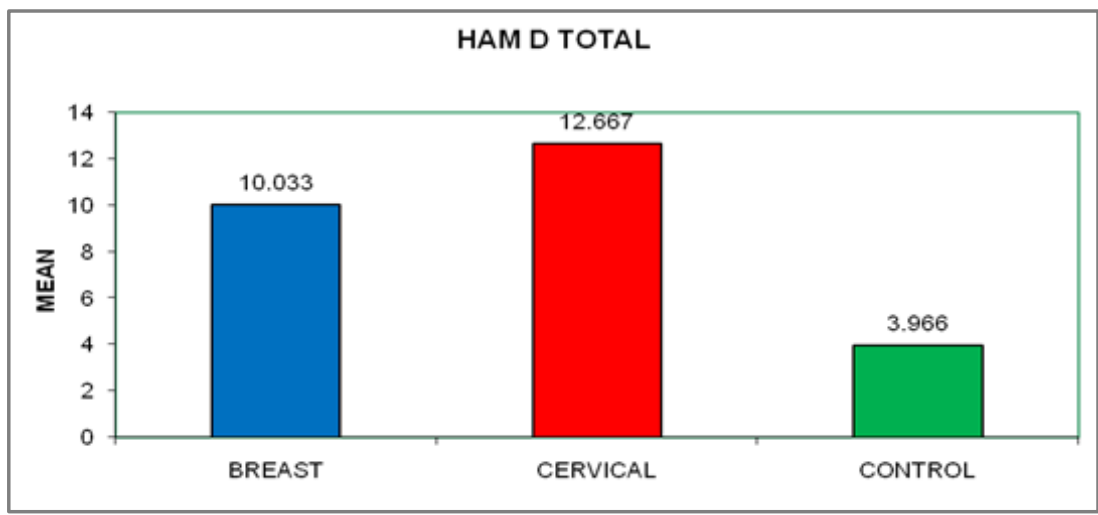

Fig. 3

When we look at psychiatric morbidity on HAM-D, the mean of HAM-D total score was 10.033 for breast cancer group, 12.666 for cervical cancer group. These groups did not differ significantly from each other $(\mathrm{P}=0.215$, NS). The mean of HAM-D total score for control group was 3.9667. The control group differ significantly from cancer groups $(\mathrm{P}=0.000$, significant) on HAM-D total score.

\begin{tabular}{|c|c|c|c|c|}
\hline HAMD & Breast & Cervix & Control & Total \\
\hline \multirow{2}{*}{ Normal } & 13 & 10 & 26 & 49 \\
& $43.3 \%$ & $33.3 \%$ & $86.7 \%$ & $54.4 \%$ \\
\hline \multirow{2}{*}{ Mild } & 4 & 7 & 3 & 14 \\
& $13.3 \%$ & $23.3 \%$ & $10.0 \%$ & $15.6 \%$ \\
\hline \multirow{2}{*}{ Moderate } & 11 & 8 & 0 & 19 \\
& $36.7 \%$ & $26.7 \%$ & & $21.1 \%$ \\
\hline \multirow{2}{*}{ Severe } & 1 & 1 & 1 & 3 \\
& $3.3 \%$ & $3.3 \%$ & $3.3 \%$ & $3.3 \%$ \\
\hline \multirow{2}{*}{ Very severe } & 1 & 4 & 0 & 5 \\
& $3.3 \%$ & $13.3 \%$ & & $5.6 \%$ \\
\hline \multirow{2}{*}{ Total } & $\mathbf{3 0}$ & $\mathbf{3 0}$ & $\mathbf{3 0}$ & $\mathbf{9 0}$ \\
& $\mathbf{1 0 0 . 0} \%$ & $\mathbf{1 0 0 . 0} \%$ & $\mathbf{1 0 0 . 0 \%}$ & $\mathbf{1 0 0 . 0} \%$ \\
\hline
\end{tabular}

Table 3: Association of breast cancer, cervical cancer and control group with severity of depression on ham-d scale

When we look at depression severity scores on HAM-D, 13 (43.3\%) cases of breast cancer, 10 (33.3\%) cases of cervical cancer and 26 (86.7\%) controls were normal, while 7 (23.3\%) cases of cervical cancer had mild depression compare to 4 (13.3\%)cases of breast cancer group and 3 (10\%) subjects of control group. Moderate depression was more in breast cancer $(36.7 \%$ cases of breast cancer group) than incervical cancer $(26.7 \%$ of patients with cervical cancer) and control. Severe depression score was same in all the three groups. Very severe depression was more in cervical cancer group 4 (13.3\%) cases. HAM-D reported 13.3\% of breast cancer had mild depression, $36.7 \%$ had moderate depression, 3.3\% had severe depression and 3.3\% had very severe depression scoring.33.3\% of cervical cancer were normal and 23.3\% had mild depression, $26.7 \%$ had moderate depression, $3.3 \%$ severe depression, and $13.3 \%$ had very severe depression. Majority of controls 


\section{ORIGINAL ARTICLE}

86.7\% were normal on HAMD scoring. Breast cancer and cervical cancer patients groups did not differ significantly from each other.Most of the control group (86.7\%) were normal and differ significantly from breast cancer and cervical cancer group $(\mathrm{p}=0.01)$ None of the study subjects had psychotic depression, the same was also reported by Buckberg et al 1984 and Derogatis et al.in 1983.4

DISCUSSION: As the concept of 'General Hospital Psychiatry' or better put 'consultation liaison psychiatry' is gaining around, more and more researches focusing on psychiatric aspects of medical diseases is coming forth. This study was undertaken to contribute to the growing body of literature in psycho-oncology worldwide, especially as data in this respect is limited for Indian population. ${ }^{5}$ The present study shows Major depressive disorder was present in $16.7 \%$ of breast cancer and $23.3 \%$ of cervical cancer patients. There was no significant association between type of cancer (Breast cancer and cervical cancer) and depressive disorder. Depression score was found high in cervical cancer cases compare to breast cancer cases though difference in these scores were not statistically significant in between two cancer groups. Depression score was high and significant in both cancer groups as compare to control group.

A landmark study by Derogatis et al, reported that $47 \%$ of a broad sample of cancer patients are qualified for at least one psychiatric diagnosis. ${ }^{1}$ In this study, few cases had more than one psychiatric disorder. Derogatis et al reported $68 \%$ of the psychiatric diagnosis consisted of adjustment disorder with depressed, anxious or mixed mood, .13\% presented with major affective disorder, $8 \%$ had organic mental disorder, $4 \%$ had anxiety disorders and $7 \%$ had personality disorder. Approximately $85 \%$ of these patients with positive psychiatric condition were experiencing a disorder with depression or anxiety as a central symptom. ${ }^{1}$ Most of the studies of psychiatric disorder in cancer patients (Derogatis et al 1983) ${ }^{1}$ were with various types and treatments of cancer.

The present study has the advantage of reducing variables that would otherwise confound interpretation of the selected variable with psychiatric diagnosis. However there is limitation of restricting the results to the specific cancer condition. Cancer cervix and cancer breast in women was chosen for the study as these are the most common and largest group of cancer seen at the cancer treating hospital in Indian population. The prevalence of major depressive disorder in general population obtained from large community studies was $2-4 \% .^{6}$ The number is more if the population studied is derived from primary care setting with prevalence ranging from 4.8 to $9.2 \%$ in ambulatory patient. ${ }^{7}$

The rate increases further among medical inpatients ranging between 27-33\%. Magni in 1986 used a structured psychiatric interview and found that $8 \%$ of the 220 geriatric medically ill inpatients suffered from major depression, 22\% had dysthymia and 6\% had atypical depression. ${ }^{8}$ Thus prevalence of major depression increases on comparing community, primary care, inpatients and severely medically ill patients. Several studies have confirmed the prevalence of depression in cancer patients in between 20 and $50 \% .9,10$

Depression in cancer patients result from stress related to cancer diagnosis and treatment, medications, biologically determined depression not related to precipitating events, and recurrence of bipolar mood disorder. A variety of other factors like past history of depression or suicidal attempts, history of alcohol dependence and other substance abuse, presence of neurotic traits, recent loss of events and frequent negative life events could also predispose to depression. 


\section{ORIGINAL ARTICLE}

In present study major depressive disorder was found in $16.7 \%$ subjects of breast cancer and 23.3\% subjects of cervical cancer patients. These results are in accordance with the studies done by Hughe, ${ }^{11}$ Morris et al.1977,12 McDaniel JS 1997,13 Lee MS et al.14 on breast cancer. Similarly the study results are also in accordance with the studies done on cervical cancer patients Evans DL et al. ${ }^{15}$ who reported 23\% major depressive disorder in cervical cancer patients. The present study showed $23.7 \%$ cases of cervical cancer patients had mild depression and $13.3 \%$ had very severe depression compare to $13.3 \%$ cases of mild depression and $3.3 \%$ cases of very severe depression in breast cancer group.

Implication: The depressive syndrome is found to influence the participation of medical care, adherence to treatment and return to the premorbid level of functioning. It also affects survival, quality of life and ability to care for one self. These facts make us to realize the necessity of prompt assessment and management of depression in cancer patients. Advanced cancer patients who are depressed may also have physical symptoms which are difficult to palliate and these symptoms improve as their depression is treated ${ }^{16}$ Depressed cancer patients have been found to have higher than normal level of interleukin-6 pro-inflammatory cytokine. Which explain the presence of increased physical symptoms in this population. Women in general have life time prevalence rate of depression between $10-21 \% .^{17}$

This study measure depression is higher in cervical and breast cancer patients than those in the general population. High prevalence of psychiatric co-morbidities in patients with cancer needs a vigorous psychiatric evaluation. An adequate knowledge of cancer related symptoms and psychosocial issues are necessary for designing any intervention program aimed at improving the quality of life of these patients.

CONCLUSION: The present study was conducted on cervical cancer patients, breast cancer patients and a control group of medically ill in patients not having cancer. The following conclusions can be drawn from this study. There is no significant association between type of cancer (Breast or cervical) and depression, though depression is more common in cervical cancer than in breast cancer. There is no significant difference in severity of depression score, in cervical and breast cancer patients. Depression score is higher in cervical cancer patients compared to breast cancer patients. Depression and severity of depression score was high and significant in both cancer groups as compare to control group, which suggests that cancer group is more vulnerable to psychiatric disorders than to other non-cancer medical illnesses.

\section{REFERENCES:}

1. Derogatis LR, Marrow GR, Fetting J, Penman D, Piasetsky S, Schmale AM et al. The prevalence of psychiatric disorder among cancer patients. Journal of American Medical Association 1983; 249: 751-757.

2. Fawzy FI, Fawzy NW, Arndt LA, Pasnau RO. Critical review of psychosocial interventions in cancer care. Arch Gen Psychiatry 1995; 52: 100-113.

3. Chandra PS, Chaturvedi SK, Channabasanvanna SM. Bibliography of Indian Research in Psycho oncology. In: Lecture Notes in Psycho Oncology.996; NIMHANS, Bangalore. 


\section{ORIGINAL ARTICLE}

4. Bukberg J, Penman D, Holland JC. Depression in hospitalzed cancer patients. Psychosomatic Med 1984; 46: 199-217.

5. Chaturvedi SK. Exploration of concerns and role of psychosocial interventions in palliative careA study from Indian Annals. Acad. Med. Singapore 1994; 12: 256-260.

6. Robind LN, Helzer JE, Weissman $M$ et al. Life time prevalence of specific psychiatric disorder in three sites. Arch Gen Psychiatry 1984; 41: 949-958.

7. Magni G, Schifano F, Leo D. Assessment of depression is an elderly medical population. J. Affective Disorder 1986; 11: 121-124.

8. Fras I, Litia EN, Pearson JS. Comparison of psychiatric symptoms in carcinoma of pancreas with those in some other intraabdominal neoplasm. American J Psychiatry 1967; 123: 1553-1562.

9. Magnire GP, Lee EG, Bevingston DJ, et al. Psychiatric problem in the first year after mastectomy. Br.Med J 1978; 1: 963-965.

10. Evan DL, McCartney CP, Nemeroff CB et al. Depression in women treated for gynaecological cancer: Clinical and neruoendocrine assessment. Am J Psychiatry 1988; 143: 447-452.

11. Hughes J. Emotional reaction and treatment of early breast cancer. Journal of Psychosomatic Research 1982; 26: 277-283.

12. Morris T, Greer HS, White P. Psychological and social adjustment to mastectomy. Cancer 1977; 40: 2381.

13. McDaniel JS, Musselman DL, Nemeroff CB. Cancer and depression: theory and treatment. Psychiatr Ann 1997; 27: 360-4.

14. Lee MS, Love SB, Mitchell JB et al. Mastectomy or conservation for early breast cancer: Psychological morbidity Eur J Cancer 1992; 28A: 1340-4.

15. Evan DL, McCartney CF, Nemeroft CB et al. Depression in women treated for gynaecological cancer: clinical and neruoendocrine assessment. Am J Psychiatry 1986; 143: 447-452.

16. Lloyd Williams M, Dennis M, Taylor F. A prospective study to determine the association between physical symptoms and depression in patients with advanced cancer. Palliative Med 2004; 18: 558-563.

17. Kessler RC, McGonazle KA, Zhao S. Lifetime and 12 month prevalence of DSM IIIR psychiatric disorders in United States: Results from the National Comorbid Survey. Arch Gen Psychiatry 1994; 51: 8-19.

\section{AUTHORS:}

1. Nimisha Mishra

2. Rajeev Dwivedi

\section{PARTICULARS OF CONTRIBUTORS:}

1. Assistant Professor, Department of Psychiatry, S. S. Medical College, Rewa.

2. Assistant Professor, Department of Anaesthesia, S. S. Medical College, Rewa.

\section{NAME ADDRESS EMAIL ID OF THE} CORRESPONDING AUTHOR:

Dr. Nimisha Mishra, Assistant Professor, Department of Psychiatry, S. S. Medical College, Rewa. E-mail: drnimishajss@gmail.com

Date of Submission: 30/01/2015. Date of Peer Review: 31/01/2015. Date of Acceptance: 03/02/2015. Date of Publishing: 06/02/2015. 